\title{
Corneal sensitivity during the menstrual cycle
}

\author{
B. RISS, S. BINDER, P. RISS, ${ }^{*}$ AND P. KEMETER* \\ From the First Department of Ophthalmology and the *Second Department of Obstetrics and \\ Gynaecology, University Hospital, Vienna, Austria
}

\begin{abstract}
SUMMARY Corneal sensitivity was determined in 5 women with regular menstrual cycles by means of a new aesthesiometer developed by Dräger. Throughout one menstrual cycle we measured corneal touch thresholds (CTT) daily and did serial determinations of urinary luteinising hormone and pregnanediol levels. CTT rose in 4 women with proved ovulation in the days before or on the day of ovulation, while corneal sensitivity remained unchanged in one anovulatory subject. We observed no changes in CTT prior to menstruation. The decrease in corneal sensitivity might be related to the preovulatory oestrogen peak.
\end{abstract}

A reduction in corneal sensitivity in the female occurs not only after operations on the eye, in various metabolic diseases, and after long-term use of contact lenses, but also in relation to physiological changes of the organism, for example during pregnancy.' Therefore one might assume that corneal sensitivity of the healthy eye also varies during the menstrual cycle. Millodot and Lamont described a significant reduction in corneal sensitivity in the days prior to the onset of menstruation. ${ }^{2}$ These authors measured corneal sensitivity in 2 women daily and in 7 women at intervals of 2 weeks during the menstrual cycle by means of a Cochet-Bonnet aesthesiometer.

With the introduction of the electromagnetic aesthesiometer of Dräger a quantitative and reproducible method for the determination of corneal touch threshold (CTT) became available. ${ }^{34}$ The purpose of the present study was to assess corneal touch thresholds with this new aesthesiometer during the menstrual cycle and to relate possible changes in corneal sensitivity to serial measurements of luteinising hormone and pregnanediol.

\section{Patients and methods}

Five healthy women between the ages of 21 and 35 years (mean age 26.8 years) with no eye disease and regular menstrual cycles volunteered for this study. Corneal touch threshold was assessed daily during one menstrual cycle. All examinations were performed by the same author in a separate room between 8 and 10 a.m. ${ }^{5}$

Correspondence to Dr Brigitte Riss. First Department of Ophthalmology, Spitalgasse 2. A-1090 Vienna. Austria.
The electromagnetic aesthesiometer of Dräger was used in order to obtain reproducible values for corneal touch threshold. ${ }^{34}$ The instrument consists of a metal tactile probe with a diameter of $0.5 \mathrm{~mm}$. In order to avoid a ballistic effect the probe is approximated with nonlinear velocity. The probe touches the cornea at a right-angle under direct vision of the examiner. The pressure of the probe can be increased continuously; pressure values are shown on a digital display between 1 and $1000 \times 10^{-5} \mathrm{~N}$.

For the determination of corneal touch threshold we selected a point on the cornea at 6 o'clock $1 \mathrm{~mm}$ from the limbus. This point was chosen because corneal sensitivity is known to be low in the centre of the cornea, and changes in corneal sensitivity would be more difficult to prove in this area. In addition the lower part of the cornea is more accessible and usually unaffected by the patient's apprehension. Care was taken not to hold the upper lid. Originally we measured CTT on both eyes. Since the differences were not significant we evaluated CTT values from the right eye only in accordance with other studies. ${ }^{6}$

The actual day of ovulation was determined by serial measurements of luteinising hormone (LH). From day 10 through day 18 samples of morning urine were assayed for $\mathrm{LH}$ by means of the immunochemical method Hi-Gonavis. ${ }^{7}$ To characterise the luteal phase urinary pregnanediol excretion was determined in night urine samples, and 24-hour pregnanediol excretion was calculated every other day from day 6 through day 28 of the menstrual cycle. ${ }^{8}$

\section{Results}

All 3 subjects with proved ovulation had CTT rises 
Fig. 1 Corneal touch thresholds $\left(C T T, \times 10^{-5} \mathrm{~N}\right)$ in 3 women (cases $1,2,3$ ) with proved ovulation, mean urinary luteinising hormone $(L H, I U / l)$, and mean pregnanediol values $(\mathrm{mg} / 24 \mathrm{~h})$. Hatched areas indicate menstruation.

immediately prior to (subject 1 and 2) or on the day of (subject 3 ) the LH peak. During the follicular and luteal phase CTT values varied between 1 and $4 \times 10^{-5}$ $\mathrm{N}$ in all women. The periovulatory rise was at least 2fold (subject 1), in subjects 2 and 3 even 4 -fold (Fig. 1).

Subject 4 had a menstrual cycle of 29 days with no LH peak and no rise in pregnanediol excretion. This patient seemed to have an anovulatory cycle, perhaps owing to oral contraceptives taken contrary to the protocol and without our knowledge (Fig. 2).

Subject 5 had a menstrual cycle of 33 days. An LH peak was not observed, since LH measurements were discontinued on day 18 . The increased pregnanediol excretion towards the end of the observation period implies ovulation around day 23-24 together with slight luteal insufficiency. Corneal touch thresholds varied between 1 and $3 \times 10^{-5} \mathrm{~N}$ with a rise to $4 \times 10^{-5}$ $\mathrm{N}$ on day 15 (Fig. 3).

\section{Discussion}

Numerous studies have been done to try to correlate ocular changes with hormonal changes during the female menstrual cycle. ${ }^{26}$ Many investigators, however, either used instruments which did not give reproducible results or failed to characterise the

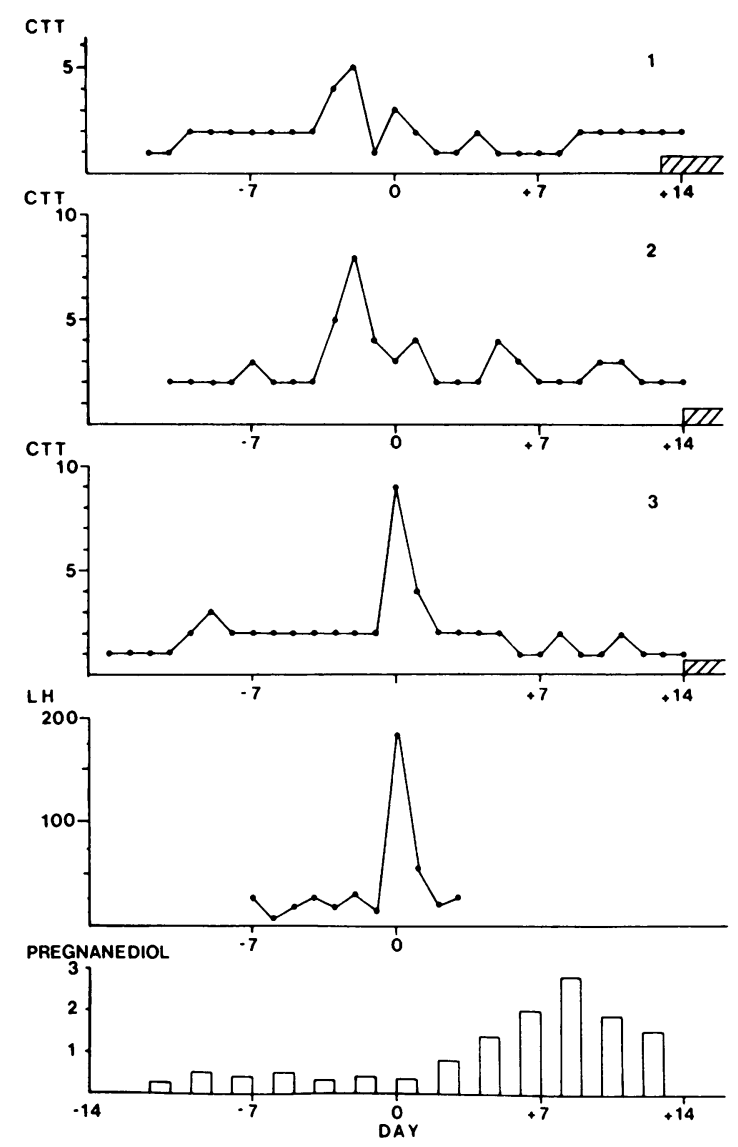

Fig. 2 Corneal touch threshold $\left(C T T, \times 10^{-5} \mathrm{~N}\right)$, urinarv luteinising hormone $(L \dot{H}, I U / l)$, and pregnanediol $(\mathrm{mg} / 24 \mathrm{~h})$ in relation to day of menstrual cycle in an anovulatory woman (case 4). Hatched area indicates menstruation.

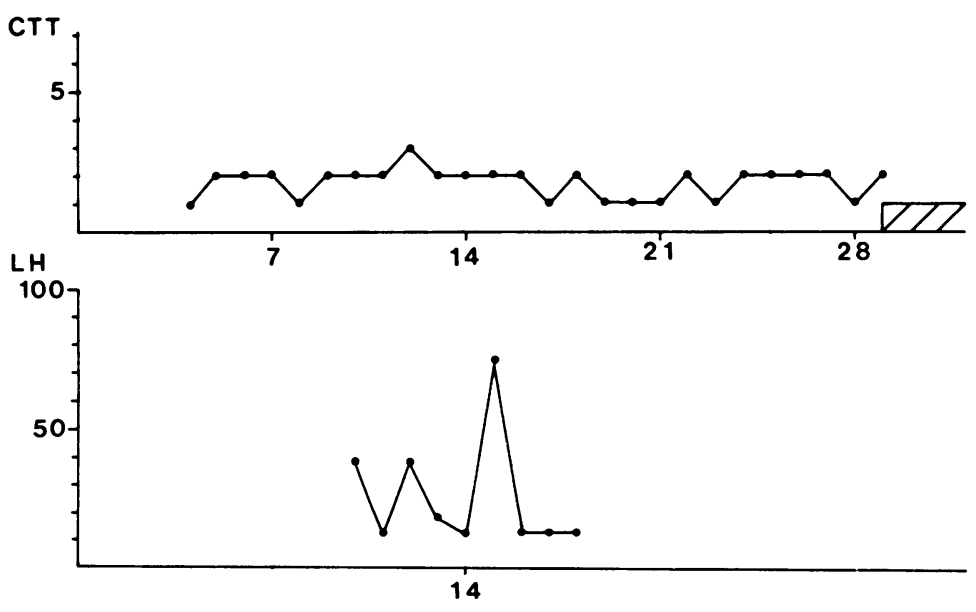

PREGNANEDIOL

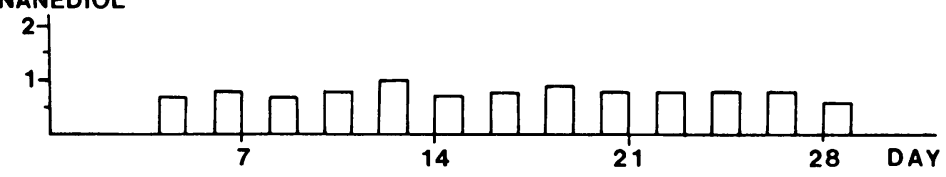




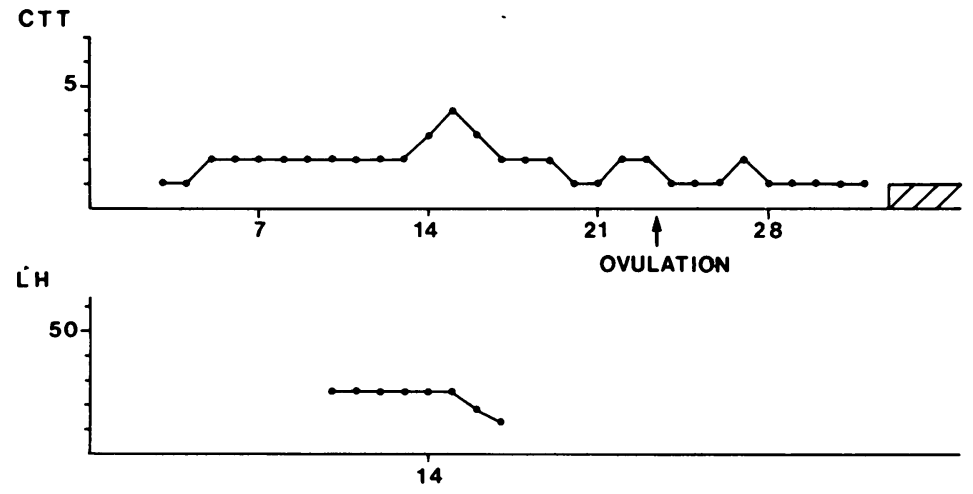

Fig. 3 Corneal touch threshold $\left(C T T, \times 10^{-5} \mathrm{~N}\right)$, urinary luteinising hormone ( $L \dot{H}, I U / l)$, and pregnanediol $(\mathrm{mg} / 24 \mathrm{~h})$ in case 5. Day of ovulation calculated according to the rise in pregnanediol excretion. Hatched area indicates menstruation.

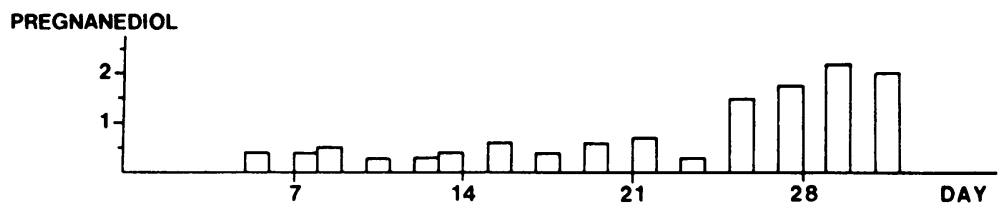

menstrual cycle adequately by means of endocrinological parameters. In a detailed study of ocular and hormonal variables throughout the menstrual cycle Feldman and coworkers ${ }^{6}$ were unable to identify significant changes in intraocular pressure, anterior chamber depth, corneal thickness, and tear production. As for corneal sensitivity, Millodot and Lamont demonstrated a premenstrual rise in corneal touch thresholds in 2 subjects but did not prove ovulation by means of endocrinological parameters. $^{2}$

Four of the 5 subjects in our study had ovulatory menstrual cycles of 28 to 33 days. CTT values varied between 1 and $3 \times 10^{-5} \mathrm{~N}$, with a 2- to 4 -fold rise just before or on the day of ovulation in 3 women. However, in subject 5 the rise in CTT occurred 7-8 days prior to the presumed day of ovulation and was less marked than in the other subjects. One patient (subject 4) had an anovulatory cycle of 29 days; corneal touch threshold values stayed constant between 1 and $3 \times 10^{-5} \mathrm{~N}$ throughout the menstrual cycle. In this cycle LH showed only a small rise on day 15 , followed by a monophasic pregnanediol excretion pattern indicative of anovulation.

Our study points towards a relationship between ovulation and reduced corneal sensitivity, since all subjects with ovulatory cycles showed a reduction in corneal sensitivity a few days before or on the day of ovulation. In the subject with an anovulatory cycle (subject 4) corneal sensitivity stayed fairly constant throughout the whole cycle. However, we were unable to confirm the premenstrual rise in CTT values described by Millodot and Lamont. ${ }^{2}$ None of our 5 subjects showed either an increase or a decrease in
CTT values in the days preceding the onset of menstruation.

Since in normal menstrual cycles a significant rise in oestrogen levels is seen 2 to 3 days prior to the $\mathrm{LH}$ peak, ${ }^{9}$ one might assume that this preovulatory oestrogen rise is related to the observed decrease in corneal sensitivity. In subject 5 CTT rose 9-10 days before the rise in pregnanediol excretion. This observation does not necessarily refute the hypothesis of a relationship between corneal touch threshold and the preovulatory oestrogen rise, since the menstrual cycle in subject 5 was prolonged and had a shortened luteal phase of 9-10 days. Since most cycles with luteal insufficiency are also characterised by a reduced preovulatory oestrogen rise, a possible explanation could be that in the menstrual cycle of subject 5 an immature follicle was luteinised around day 19 , but a subsequent low LH peak caused only a delayed luteinisation with a delayed rise in urinary pregnanediol values.

Though our study provides some evidence for a relationship between oestrogen and corneal sensitivity, definite proof has not yet been provided. In addition it is not clear whether oestrogen has a direct effect on the eye or acts indirectly via intraocular pressure, corneal oedema, or circulatory changes in the eye. So long as the exact mechanisms responsible for changes in corneal sensitivity remain to be elucidated it will be difficult to establish a clear-cut relationship between any one parameter and corneal sensitivity.

\section{References}

1 Riss B. Riss P. Corneal sensitivity in pregnancy. Ophthalmologica 1981: 183: $57-62$. 
2 Millodot M. Lamont A. Influence of menstruation on corneal sensitivity. Br J Ophthalmol 1974; 58: 752-56.

3 Dräger J. Klinische Ergebnisse der Aesthesiometrie der Hornhaut. Ber Dtsch Ophthalmol Ges 1976; 76: 389-95.

4 Dräger J. Koudelka A. Lubhan E. Zur Ästhesiometrie der Hornhaut. Klin Monatsbl Augenheilkd 1976; 169: 407-21.

5 Millodot M. Diurnal variation of corneal sensitivity. Br J Ophthalmol 1972; 56: 844.

6 Feldman F. Bain J, Matuk AR. Daily assessment of ocular and hormonal variables throughout the menstrual cycle. Arch Ophthalmol 1978: 96: 1835-8.
7 Kemeter P. Wögerbauer CH. Gring H. Salzer H. Friedrich F. Breitenecker G. Der Vergleich zweier Methoden der LHBestimmung im Harn (Luteonosticon ${ }^{R}$ und HI-Gonavis ${ }^{R}$ ). mit LH. FSH. Ostradiol. Progesteron. Testosteron und Prolactin im Serium beim Konzeptionsoptimum. Wien Klin Wochenschr 1979: 91: 118-22.

8 Friedrich F. Kemeter P. Die Aussagekraft der weiblichen Pregnandiolausscheidungskurve. Wien Klin Wochenschr 1973: 85: $362-65$.

9 Yen SSC. The human menstrual cycle. In: Yen SSC. Jaffe RD. eds. Reproductive Endocrinologv. Philadelphia: Saunders. 1978: 126-51. 